\title{
Emotional Security and Social Competence among Syrian Refugee Children with Learning Disabilities
}

\author{
Hisham Almakanin ${ }^{1}$, Ali Olaimat ${ }^{1}$, Omayya Al-Hassan ${ }^{1}$, Ali Alodat ${ }^{2, *}$, Ayoub Al-Rousan ${ }^{1}$ \\ ${ }^{1}$ Queen Rania Faculty for Childhood, Hashemite University, Zarqa, Jordan \\ ${ }^{2}$ College of Education, Yarmouk University, Irbid, Jordan
}

Received November 13, 2020; Revised December 19, 2020; Accepted January 20, 2021

\begin{abstract}
Cite This Paper in the following Citation Styles
(a): [1] Hisham Almakanin, Ali Olaimat,, Omayya Al-Hassan, Ali Alodat, Ayoub Al-Rousan, "Emotional Security and Social Competence among Syrian Refugee Children with Learning Disabilities," Universal Journal of Educational Research, Vol. 9, No. 1, pp. 231 - 240, 2021. DOI: 10.13189/ujer.2021.090125.
\end{abstract}

(b): Hisham Almakanin, Ali Olaimat,, Omayya Al-Hassan, Ali Alodat, Ayoub Al-Rousan (2021). Emotional Security and Social Competence among Syrian Refugee Children with Learning Disabilities. Universal Journal of Educational Research, 9(1), 231 - 240. DOI: 10.13189/ujer.2021.090125.

Copyright $\bigcirc 2021$ by authors, all rights reserved. Authors agree that this article remains permanently open access under the terms of the Creative Commons Attribution License 4.0 International License

\begin{abstract}
Emotional security and social competence are considered crucial psychological factors that affect the learning process, especially among vulnerable groups such as refugees and people with disabilities. This study aimed to identify the level of emotional security and social competence among Syrian refugees' children with learning disabilities. To achieve this objective, a descriptive-analytical approach was used to identify the level of emotional security, and social competence among (161) Syrian refugee children with learning disabilities enrolled in resource rooms in schools in the Zarqa Governorate, Jordan. The participants responded to emotional security and social competence scales. The results showed statistically significant differences in emotional security among Syrian refugees' children with learning disabilities attributed to their gender in favor of female children. At the same time, there was no difference in emotional security level based on parental status. The results also revealed statistically significant differences in social competence level based on the parental status for those who live with their parents. In general, the results showed a positive correlation between emotional security and social competence in children with learning disabilities from refugees. This study highlights the importance of conducting training programs to increase the level of emotional security, academic skills, and social behavior among refugee children with learning disabilities.
\end{abstract}

Keywords Emotional Security, Social Competence, Children with Learning Disabilities, Syrian Refugees

\section{Introduction}

Students with specific learning disabilities are considered a heterogeneous group not only in their academic achievement but also in their cognitive, behavioral, and social characteristics $[1,2]$. Considering social characteristics, students with learning disabilities have difficulty taking personal or social responsibility and self-control [3]. Social participation benefits of students with learning disabilities in inclusive settings vary according to the type of learning difficulty, grade level, peer attitudes, and students' social competence [4]. Reference [5] reviewed 152 studies on social skills and showed that $75 \%$ of students with learning disabilities have social skills deficits. Indeed, other studies indicated that $34 \%-59 \%$ of students with learning disabilities are exposed to social and educational problems, such as aggression, personal inadequacy, coping problems in school, integration with others, and participation activities $[6,7,8]$. Children with learning disabilities are at greater risk of social hardship than other students; besides, those children do not show accurate self-observations of social acceptance [9]. Likewise, children with low learning achievement have low social competencies and fewer friends than other students [10]; however, friendship has a more significant role in achieving social competence among students with learning disabilities [11]. 


\subsection{Social Competence}

Syrian refugees' children are vulnerable to war's harmful effects, such as psychological, social, educational effects $[12,13,14,15]$. The latest statistics issued by the United Nations Children's Fund (UNICEF) indicate that the number of children living in dangerous situations inside and outside Syria has reached 5.5 million Syrian children, and the number of students enrolled in schools does not exceed $47 \%$ of the total number in the five neighboring countries [16]. Other international organizations, such as the United Nations Refugee Agency (UNHCR), also have cautioned against the worsening effects of asylum on children, especially in the psychosocial and educational aspects [17]. In Jordan, the Ministry of Education statistics indicated that the number of Syrian refugee children enrolled in Jordanian schools was more than 100 thousand. In Zarqa Governorate, there were 5,520 students; among those, 1,048 students were classified as students with learning disabilities [18]. These students' problem is not limited to suffering from learning disabilities but extends to suffering from social problems, which may be due to the lack of social skills, social competence, and low perception of social attitudes. Whatever the reason behind the lack of social competence, this weakness makes it more likely for students to fail academically and socially [19]. Social competence problems among refugee children with learning disabilities may increase when there are low levels of emotional security $[20,21]$. The decrease in emotional security in children with social learning disabilities is correlated with low academic achievement and weak emotional growth [22].

\subsection{Emotional Security}

Emotional security is the first source of the individual's sense of self and others [23], and the need for sharing a feeling, dignity need, and perfecting life [24]. However, individuals develop their emotional safety through acceptance, respect, belonging, familiarity, scarcity of threat and anxiety, confidence, and social affiliation, which provide reassurance and stability for human beings [25]. On the other hand, emotional security is the stabilization of the emotional state, where feelings of uneasiness, stress, or nervousness may expose individuals to the risk of a low level of emotional security [26]. This risk dramatically increases when accompanied by fear, trauma, deprivation, and want [27]. The need for emotional security in children with learning disabilities from Syrian refugees would crystallize as one of the necessary mental health needs, especially if they experienced traumatic situations [28, 29]. Reference [30] reported that the most critical factors affecting students' emotional security are the cooperation of the school administration and the positive relations between teachers and students themselves. Reference [31] indicated a significant correlation between academic optimism, emotional security, and school environment. The study showed that female students are more optimistic but less secure than males; in addition to that, students in the higher school stages are more self-confident than students in the lower school stages. In addition, students in higher grades are more reassuring and self-confident than students in lower grades. Other studies argued that an emotionally safe child has higher levels of positive social behavior, and students' emotional security can be predicted in light of self-confidence and social competence $[32,33]$. Social behavior and emotional security are also vital to the quality of life, especially since the relationship between them is correlative and positive [34].

In the context of refugees' emotional security, Reference [35] reported a high level of psychological security among Syrian refugee students, especially among male students. Reference's [36] study showed that (63\%) of (190) Syrian refugee students participated in the study have a low level of emotional security while only $(3.6 \%)$ of the study participants have a high level of emotional security. Reference [37] reported an average level of social consensus and emotional security among refugee students attending public schools in Madaba governorate, Jordan. The results also indicated no statistically significant differences in the level of social compatibility and emotional security, according to gender, duration of asylum, and parents' presence.

\subsection{Refugee Children with Learning Disabilities}

Refugee children differ in their responses to the new school environment, depending on their age, psychosocial state, and the services provided by educational institutions in the host countries [38]. However, the adaptation process in schools faced greater challenges and obstacles if refugee children are diagnosed with learning disabilities [39]. The term "learning disability" refers to a disorder in understanding or using language and mathematical calculations, which does not cause by other sensory and intellectual disabilities or by socio-cultural and economic factors [40]. There is a lack of studies investigating learning disabilities among refugee children; nevertheless, some studies considered refugees as a minority group and investigated learning disabilities within this domain [41]. Reference [42] indicated that the learning experiences of refugee children with learning disabilities are affected by the school environment, learning resources, and social environment. Specifically, the Reference [42] divided the errors that cause difficulties facing refugee children with learning disabilities into two major errors: linguistic and social evaluation and the providing support in schools. Reference [43] emphasized that schools play a critical role in shaping young refugees with disabilities' social identities. So, refugee children with disabilities' social and 
personal experiences are considered the backbone of inclusive schools' cultures. Therefore, exploring the social and emotional characteristics of refugee children with learning disabilities contributes to these children's progress and educational institutions.

\subsection{Study Problem and Questions}

Asylum circumstances forced Syrian refugee children had to live in new communities and different educational environments. More importantly, these circumstances became more difficult for children with disabilities, especially when interacting with other children within this social context. Furthermore, although other foreign and Arab studies were targeting refugees to describe their reality, needs, asylum effects, and levels of support, these studies were limited to refugee children in general. A few of these studies targeted refugee children with learning disabilities. This prompted the researchers to conduct this study to identify the level of emotional security and its relationship to social competence in children with learning disabilities of Syrian refugees to address the following questions:

- What is the level of emotional security among children with learning disabilities from Syrian refugees in the Zarqa Governorate?

- What is the level of social competence among children with learning disabilities from Syrian refugees in the Zarqa Governorate?

- Does the level of emotional security among children with learning disabilities from Syrian refugees in the Zarqa governorate differ by gender and parental status?

- Does the level of social competence among children with learning disabilities from Syrian refugees in the Zarqa governorate differ according to their gender and parental status?

- What is the relationship between the level of emotional security and social competence among children with learning disabilities from Syrian refugees in the Zarqa Governorate?

The study's theoretical significance lies in helping specialists and teachers in educational institutions identify the levels of emotional security and social competence among Syrian refugee children with learning disabilities. The results will also help teachers, practitioners, and educational policymakers effectively plan and implement special education programs in the school resource rooms. Furthermore, exploring the nature of the relationship between emotional security and social competence among refugee children with learning disabilities will enrich theoretical literature in Jordan and neighborhood countries in the field of special education. In a related way, the study's practical significance is evident in the fact that the results would help teachers and practitioners develop training programs to improve emotional security and increase social competence among refugee children with learning disabilities. The present study provides improved scales that could be used in subsequent studies related to emotional security and social competence among children with learning disabilities from Syrian refugees.

\section{Materials and Methods}

\subsection{Participants}

The participants in this study were (161) Syrian refugee students with learning disabilities between the ages of (9-12) who were diagnosed by the Ministry of Education and chosen intentionally. The participants were enrolled in five elementary schools located in Zarqa educational district, Zarqa Governorate. Table 1 illustrates the participant's information.

Table 1. Distribution of Study Sample by gender and Parental Status

\begin{tabular}{cccc}
\hline Variable & Variable levels & Number & Percentage \\
\hline \multirow{3}{*}{ Gender } & Male & 96 & $59.63 \%$ \\
& Female & 65 & $40.37 \%$ \\
& Total & 161 & $100 \%$ \\
& $9-10$ & 60 & $37.27 \%$ \\
Age & $11-12$ & 101 & $62.73 \%$ \\
& Total & 161 & $100 \%$ \\
& $\begin{array}{c}\text { Living with } \\
\text { parents }\end{array}$ & 73 & $45.34 \%$ \\
& $\begin{array}{c}\text { Living with one } \\
\text { parent }\end{array}$ & 48 & $29.81 \%$ \\
Status & $\begin{array}{c}\text { Living in the } \\
\text { absence of } \\
\text { parents } \\
\end{array}$ & 40 & $24.84 \%$ \\
& Total & 161 & $100 \%$ \\
\hline
\end{tabular}

\subsection{Instruments}

The researchers referred to the educational literature and previous standards related to the current study to develop the Emotional Security Scale for Refugee Children (ESSRC). Specifically, the ESSRC developed based on previous literature [32, 35]. Initial content validity was established by sending the ESSRC's items to twelve experts on psychology and special education, including faculty members, psychologists, and graduate students. The experts were asked to review and evaluate the items' clarity and suitability for the study objectives. Any item that was deleted by three experts was removed from the first version of the scale. In addition, the researchers made the required adjustments requested by experts, such as language or terminology changes. To verify the reliability of the ESSRC, the Cronbach Alpha equation was used. The results of the analysis showed a high degree of stability of the scale, which was (0.84). The final version of ESSRC consisted of (44) items 
distributed over four domains: self-confidence, self-assertion, safety in social interactions, and social acceptance (Appendix 1).

To measure social competence, the researchers developed the Social Competence Scale for Refugee Children (SCSRC) based on related literature $[6,44]$. The researchers have extracted the SCSRC content validity indicators by asking twelve experts in psychology and special education at Hashemite University to review the instrument items. Experts reviewed the scale items in terms of appropriateness, clarity, and items' pertinence to dimensions. The reviewers only recommended minor changes in phrases and vocabularies in the SCSRC. However, the researchers made the required adjustments to the scale. Also, the researchers used the Cronbach Alpha equation to measure the scales' reliability indicators. The results showed the scales' reliability, where the degree of reliability was (0.88). The final version of SCSRC consisted of (30) items distributed over three domains: Perceptive interpersonal skills, Self-control and management skills, academic behavior skills (Appendix 2). In general, the study instruments used the Arabic language and distributed on a graduated answer scale according to Likert's five-step scale as follows: Always (4), Often (3), Sometimes (2), Rarely (1), Never (0).

\subsection{Procedures}

The researchers obtained the required permissions from the Ministry of Education to conduct this study. The researchers visited schools located in refugee camps and collected consent forms from parents of students with learning disabilities. Then, the researchers met with students to clarify the study's purpose and distribute the study instruments. The study instruments were read to students, and researchers registered their responses to assure that students fully understand the scales' items. However, the researchers comply with the Ethical Standards of Conducting Scientific Researches at Hashemite University to conduct this study.

\subsection{Data Analysis}

This study used a descriptive approach to identify the relationship between emotional security and social competence among Syrian refugee children with learning disabilities. The researchers computed means and standard deviations to answer the first and second questions, and they used the Multivariate analysis of variance test (MANOVA) to answer the third and fourth questions. As for the fifth question, the Pearson Correlation Coefficient Formula was used to identify the relationship between emotional security levels and social competence among Syrian refugee children with learning disabilities.

\section{Results}

The results showed that level of emotional security among Syrian refugee children with learning disabilities was generally moderate. Table 2 illustrates the calculated means and standard deviations of the ESSRC main dimensions.

Table (2) shows that the overall performance score on the ESSRC was (2.73) and the standard deviation was (0.522). The order of the scale dimensions in terms of average was as follows: social acceptance (2.76), social interactions (2.74), self-confidence (2.71), then self-assertion (2.71).

Table 2. Means and standard deviations of the ESSRC dimensions

\begin{tabular}{ccccc}
\hline Dimension & M & SD & Min & Max \\
Social Acceptance & 2.76 & 0.610 & 1 & 5 \\
Social Interactions & 2.74 & 0.589 & 1 & 5 \\
Self-confidence & 2.71 & 0.692 & 1 & 5 \\
Self-assertion & 2.71 & 0.606 & 1 & 5 \\
Total & 2.73 & 0.552 & & \\
\hline
\end{tabular}

The results also showed that the level of social competence among Syrian refugee children with learning disabilities was generally moderate. Table 3 illustrates the calculated means and standard deviations of the SCSRC dimensions. Table (3) shows that the total score of performance on the SCSRC was (2.68), and a standard deviation was $(0.700)$. The order of the scale dimensions in terms of average was as follows: perceived personal skills (2.77), self-control, and management skills (2.64), then academic behavior skills (2.63).

Table 3. Means and standard deviations of the ESSRC dimensions

\begin{tabular}{ccccc}
\hline Dimension & M & SD & Min & Max \\
Perceptive Skills & 2.77 & 0.664 & 1 & 5 \\
Self-control & 2.64 & 0.829 & 1 & 5 \\
Academic Skills & 2.63 & 0.734 & 1 & 5 \\
Total & 2.68 & 0.700 & & \\
\hline
\end{tabular}

To determine if the level of emotional security among Syrian refugee children with learning disabilities is differed by gender (male, female) and parental status (Living with parents, living with one parent, and living in the absence of parents), means and standard deviations of the participants' responses on the ESSRC according to the study variables were calculated as shown in Table (4). 
Table 4. Means and standard deviations of the ESSRC according to the study variables

\begin{tabular}{ccccccccccccc}
\hline \multirow{2}{*}{ Variables } & Level & \multicolumn{2}{c}{ Self-confident } & \multicolumn{2}{c}{ Self - assertion } & \multicolumn{2}{c}{$\begin{array}{c}\text { Social } \\
\text { Interaction }\end{array}$} & \multicolumn{2}{c}{$\begin{array}{c}\text { Social } \\
\text { Acceptance }\end{array}$} & \multicolumn{2}{c}{ Total } \\
\cline { 3 - 12 } & & M & SD & M & SD & M & SD & M & SD & M & SD \\
\cline { 3 - 12 } Gender & Males & 2.49 & 0.42 & 2.47 & 0.42 & 2.47 & 0.36 & 2.47 & 0.43 & 2.47 & 0.37 \\
& Females & 3.04 & 0.68 & 3.18 & 0.59 & 3.15 & 0.62 & 3.08 & 0.82 & 3.11 & 0.55 \\
& with parents & 2.68 & 0.54 & 2.66 & 0.48 & 2.64 & 0.50 & 2.66 & 0.57 & 2.66 & 0.48 \\
Parental & Status & single parent & 2.62 & 0.67 & 2.63 & 0.62 & 2.73 & 0.58 & 2.64 & 0.74 & 2.65 & 0.56 \\
& without parents & 2.86 & 0.61 & 3.08 & 0.68 & 2.95 & 0.68 & 2.90 & 0.80 & 2.95 & 0.60 \\
\hline
\end{tabular}

Table 5. Analysis of Multiple Binary variances of the impact of gender and parental status on Emotional Security

\begin{tabular}{|c|c|c|c|c|c|c|}
\hline SV & Emotional security & SS & DF & $\mathbf{M}$ & $\mathbf{F}$ & Sig \\
\hline \multirow{4}{*}{ *Gender } & Self-confident & 11.767 & 1 & 11.767 & 40.448 & 0.00 \\
\hline & Self - assertion & 14.968 & 1 & 14.968 & 60.328 & 0.00 \\
\hline & Social Interactions & 16.369 & 1 & 16.369 & 70.114 & 0.00 \\
\hline & Social Acceptance & 14.045 & 1 & 14.045 & 36.198 & 0.00 \\
\hline \multirow{4}{*}{$\begin{array}{l}* * \text { Parental } \\
\text { Status }\end{array}$} & Self-confident & 1.442 & 2 & 1.442 & 2.478 & 0.08 \\
\hline & Self - assertion & 1.044 & 2 & 1.044 & 2.104 & 0.12 \\
\hline & Social Interactions & 0.653 & 2 & 0.653 & 1.399 & 0.25 \\
\hline & Social Acceptance & 1.219 & 2 & 1.219 & 1.570 & 0.21 \\
\hline \multirow{4}{*}{ Error } & Self-confident & 45.675 & 157 & 0.291 & & \\
\hline & Self - assertion & 38.954 & 157 & 0.248 & & \\
\hline & Social Interactions & 36.654 & 157 & 0.233 & & \\
\hline & Social Acceptance & 60.917 & 157 & 0.388 & & \\
\hline \multirow{5}{*}{$\begin{array}{l}\text { Adjusted } \\
\text { Total }\end{array}$} & Self-confident & 58.835 & 160 & & & \\
\hline & Self - assertion & 59.598 & 160 & & & \\
\hline & Social Interactions & 55.522 & 160 & & & \\
\hline & Social Acceptance & 76.810 & 160 & & & \\
\hline & Total & 48.160 & 160 & & & \\
\hline
\end{tabular}

*Gender: Hotelling $=0.514, \mathrm{df}=0.00 ; * *$ Parental Status: Wilkes $=0.924, \mathrm{df}=0.14$

Table 6. Means and standard deviations of the SCSRC according to the study variables

\begin{tabular}{|c|c|c|c|c|c|c|c|c|c|}
\hline \multirow{2}{*}{ Variables } & \multirow{2}{*}{ Level } & \multicolumn{2}{|c|}{ Interpersonal Skills } & \multicolumn{2}{|c|}{ Self-control } & \multicolumn{2}{|c|}{ Academic Skills } & \multicolumn{2}{|c|}{ Social Efficiency } \\
\hline & & $\mathbf{M}$ & SD & $\mathbf{M}$ & SD & $\mathbf{M}$ & SD & $\mathbf{M}$ & SD \\
\hline \multirow{2}{*}{ Gender } & Males & 2.84 & 0.71 & 2.75 & 0.70 & 2.75 & 0.82 & 2.78 & 0.71 \\
\hline & Females & 2.65 & 0.57 & 2.46 & 0.74 & 2.47 & 0.80 & 2.53 & 0.65 \\
\hline \multirow{3}{*}{$\begin{array}{c}\text { Parental } \\
\text { Status }\end{array}$} & with parents & 2.90 & 0.73 & 2.85 & 0.75 & 2.87 & 0.85 & 2.87 & 0.74 \\
\hline & single parent & 2.66 & 0.60 & 2.44 & 0.71 & 2.44 & 0.85 & 2.51 & 0.65 \\
\hline & without parents & 2.65 & 0.56 & 2.47 & 0.61 & 2.46 & 0.64 & 2.53 & 0.59 \\
\hline
\end{tabular}

Table (4) shows differences in emotional security based on the participants' responses to the ESSRC dimensions. To find out the significance of the means' differences, the Multivariate Indication (Two Way MANOVA) was used, as shown in Table (5).

Table (5) shows statistically significant differences in the level of emotional security in general and for the scale dimensions due to the gender variable. The $F$ values of the emotional security level were (68.669), and it was (40.448) for the self-confidence dimension, (60.328) for the self-assertion, (70.114) for the social interactions, and (36.198) for the social acceptance. Table (4) also shows that the emotional security level in general among female students (3.11) was higher than male students (2.47), and it was higher among female students than male students in all dimensions. As shown in Table (5), there were also no statistically significant differences in the level of emotional security and its dimensions due to the parental status variable. To find out if the level of social competence among Syrian refugee children with learning 
disabilities is differed by gender (male, female) and parental status (Living with parents, living with one parent, and living in the absence of parents), means and standard deviations of participants' responses on the SCSRC were calculated as shown in Table (6).

Table (6) shows differences in the means of the social competence level and its three dimensions (perceived personal skills, Self-control and management skills, academic behavior skills). A Two-Way analysis (MANOVA) test was used to determine the significance of these differences, as shown in Table (7).

Table (7) shows no statistically significant differences in the level of social competence in general and its three dimensions due to the gender variable. As shown in Table (7), there are statistically significant differences in the level of social competence in general and the dimensions of self-control and academic skills attributed to the parental status variable, where the $\mathrm{F}$ value of for social competence was (3.294), (3.862) for self-control, and $(3,455)$ for academic skills. To determine the significance of differences in social competence according to the parental status variable, the Scheffe test was used for dimensional comparisons, as shown in Table (8).

Table (8) shows statistically significant differences in the level of social competence and the self-control dimension. The academic skills dimension is congruent to the parental status variable, as the level of social competence in general, the level of self-control, and the academic skills among students living with their parents are higher than for students living with one parent without their parents.

Table 7. Analysis of Multiple Binary variances of the impact of gender and parental status on Social Competence

\begin{tabular}{|c|c|c|c|c|c|c|}
\hline SV & Social Competence & SS & DF & $\mathbf{M}$ & $\mathbf{F}$ & Sig \\
\hline \multirow{4}{*}{ *Gender } & Interpersonal Skills & 0.380 & 1 & 0.380 & 0.879 & 0.35 \\
\hline & Self-control & 0.853 & 1 & 0.853 & 1.689 & 0.19 \\
\hline & Academic Skills & 0.601 & 1 & 0.601 & 0.921 & 0.33 \\
\hline & Social efficiency & 0.596 & 1 & 0.596 & 1.282 & 0.25 \\
\hline \multirow{4}{*}{$\begin{array}{c}* * \text { Parental } \\
\text { Status }\end{array}$} & Interpersonal Skills & 1.330 & 1 & 1.330 & 1.536 & 0.21 \\
\hline & Self-control & 3.903 & 1 & 3.903 & 3.862 & 0.02 \\
\hline & Academic Skills & 4.510 & 1 & 4.510 & 3.455 & 0.03 \\
\hline & Social efficiency & 3.062 & 1 & 3.062 & 3.294 & 0.04 \\
\hline \multirow{4}{*}{ Error } & Interpersonal Skills & 67.987 & 157 & 0.433 & & \\
\hline & Self-control & 79.342 & 157 & 0.505 & & \\
\hline & Academic Skills & 102.462 & 157 & 0.653 & & \\
\hline & Social efficiency & 72.968 & 157 & 0.456 & & \\
\hline \multirow{4}{*}{ Adjusted Total } & Interpersonal Skills & 70.693 & 160 & & & \\
\hline & Self-control & 86.414 & 160 & & & \\
\hline & Academic Skills & 109.996 & 160 & & & \\
\hline & Social efficiency & 78.476 & 160 & & & \\
\hline
\end{tabular}

${ }^{*}$ Gender: Hotelling $=0.012, \mathrm{df}=0.59 ; * *$ Parental Status: Wilkes $=0.948, \mathrm{df}=0.21$

Table 8. Scheffe test results for dimensional comparisons according to the parental status variable

\begin{tabular}{cccccc}
\hline Dimensions & Level of study & M & With Parents & One Parent & $\begin{array}{c}\text { Without } \\
\text { Parents }\end{array}$ \\
\hline \multirow{3}{*}{ Self-control } & With Parents & 2.85 & & 0.41 & 0.38 \\
& One Parent & 2.44 & -0.41 & & \\
& Without Parents & 2.47 & -0.38 & & 0.41 \\
\cline { 2 - 6 } Academic Skills & With Parents & 2.87 & & 0.43 & 0.34 \\
& One Parent & 2.44 & -0.43 & & \\
Sithout Parents & 2.46 & -0.41 & & \\
Competence & With Parents & 2.87 & & & \\
\hline
\end{tabular}


To determine the relationship between emotional security and social competence among Syrian refugee children with learning disabilities, the Pearson correlation coefficient was calculated on participants' performance, as shown in table (9).

Table 9. Correlation coefficients between emotional security and social competence

\begin{tabular}{|c|c|c|c|c|c|}
\hline V & D1 & D2 & D3 & D4 & D5 \\
\hline $\begin{array}{c}\text { Interpersonal } \\
\text { Skills }\end{array}$ & 0.58 & 0.64 & 0.65 & 0.68 & 0.50 \\
\hline Self-control & 0.34 & 0.42 & 0.36 & 0.45 & 0.48 \\
\hline $\begin{array}{l}\text { Academic } \\
\text { Skills }\end{array}$ & 0.45 & 0.34 & 0.52 & 0.34 & 0.42 \\
\hline $\begin{array}{c}\text { Social } \\
\text { Competence }\end{array}$ & 0.53 & 0.48 & 0.66 & 0.62 & 0.60 \\
\hline
\end{tabular}

D1: Self-confident, D2: Self - assertion, D3: Social Interactions,

D4: Social Acceptance, D5: Emotional Security

Table (9) shows a direct relationship between emotional security and social competence among Syrian refugee children with learning disabilities. The Table also shows a direct correlation and statistically significant relationship between the dimensions of the ESSRC and the dimensions of the SCSRC, where the values of correlation coefficients ranged between (0.34- 0.68).

\section{Discussion}

The results showed a moderate level of emotional security among Syrian refugees' children with learning disabilities. The researchers attribute the moderate level of emotional security among Syrian refugee children with learning disabilities to the availability of a set of factors contributing to the psychological security of those children, such as the nature of the educational environment, the cooperation of school management, and the positive relations between teachers and students. Besides, the supportive psychological trends of peers and people interacting with refugee children, especially that there is a general understanding in the educational community of the nature of the circumstances experienced by those children [30]. Regarding the order of the emotional security dimensions of Syrian refugee children with learning disabilities, the researchers believe this arrangement is logical. For example, the dimension of social acceptance ranked first because the educational policy in Jordan does not discriminate between students based on their nationality, and all students are equal. Furthermore, Syrian refugee children are socially accepted and provided with adequate social interactions to support students' self-confidence and self-assertion; this explains why students with refugee children with learning disabilities feel socially accepted.

Regarding social interactions, this study's results indicated that refugee children learning disabilities are socially interacted with their teachers and other students, which provide greater levels of psychological, emotional, social, and educational support for those children. This finding is consistent with some studies' findings [30, 37]. In contrast, this result is different from a study that indicated a moderate level of refugee students' sense of self and emotional security [35]. Moreover, the current result is also different from the result that reported a low level of emotional security among refugee students with learning disabilities of insecurity, violence, and limited educational opportunities [7,36].

On the other hand, the researchers attribute the moderate level of social competence among refugee children with learning disabilities to the social interaction skills and active participation in different situations that Syrian refugee children with learning disabilities have achieved in schools. This includes knowledge of acceptable behavior, the ability to solve social problems, and identifying and understanding emotions. The researchers also attribute this result to emotional security among refugee children with learning disabilities, accompanied by a moderate level of psychological and social skills. However, this moderate level of social competence results from educational support provided by teachers and social participation provided by peers. This result is consistent with some studies [37]; in contrast, it differs from studies' results that indicated that children with low learning attainment have low social competencies and they are at greater risk in terms of social disabilities and most suffering from behavioral problems $[9,10]$.

As for the differences in emotional security in favor of female Syrian refugee children with learning disabilities, the researchers attribute it to the general atmosphere in the place of asylum and the psychological stability of individuals. To illustrate, most of the female participants of this study were living with their parents, and others were living with one parent; thus, there is no doubt that parents' presence in general or one of them reflected positively on the reality of the emotional security individuals. The researchers also attribute the result to the duration of asylum, which is more than five years, which is most of the participants in this study. Regarding the level of social competence, the researchers believe that there is a significant role in their children's personal social and academic behavior. The majority of the study participants were living with their families in a way that affected their personal, social, and academic behaviors. Researchers also attribute the positive and functional relationship between emotional security and social competence to the feeling of comfort, contentment, and happiness among children, which allows them to interact positively and participate actively in society. This positive interaction will promote self-confidence and drive children to be social by behavior; accordingly, this finding is consistent with the results that pointed out that there is a positive and significant relationship between emotional 
security of students on the one hand and their social competence on the other hand [33,34].

\section{Conclusions}

The results of this study fill a gap in the literature regarding the psychological characteristics of refugee children with disabilities. As illustrated, there is a lack of studies that investigated emotional security and social competences among refugee children in general and particularly with learning disabilities. In fact, such psychological factors play a great role in the adaptation of refugee children with learning disabilities in schools [39]. In the light of the findings of the study, the researchers recommend the need to conduct other studies to determine the reality of emotional security among refugee children with learning disabilities according to other variables related to the child's age, nationality, duration of asylum, place of asylum and nature of learning disabilities. This study also encourages other researchers to explore the relationship between emotional security and other variables, such as motivation for learning and citizenship. The researchers also argue the need to conduct training programs to increase the level of emotional security, especially in the field of self-assurance support. Besides, this study recommends training programs to increase academic and social behavior among refugee children with learning disabilities through the activation and development of learning resources rooms. On the other hand, the limitations of this study lie in place bounders, participants' age, and other related factors. First, this study targeted Syrian refugee children with learning disabilities in one governance in Jordan, which may affect the results' generalizability. In addition, the participants' age in this study was 9-12 years old, which restricted the generalizability of results over children of other ages. Finally, the results of this study might be affected by other unidentified factors, such as the learning disabilities' type.

\section{Acknowledgements}

The authors of this study have received no funds to conduct this research; moreover, the authors have no conflict of interest. Indeed, the authors are very grateful to reviewers for their time and constructive suggestions to improve this article.

\section{REFERENCES}

[1] Fletcher, J. M., Lyon, G. R., Fuchs, L. S., \& Barnes, M. A. Learning Disabilities, Second Edition: From Identification to Intervention. Guilford Publications. (2018).

[2] Hallahan, D. P., Pullen, P. C., Kauffman, J. M., \& Badar, J.
Exceptional Learners. In D. P. Hallahan, P. C. Pullen, J. M. Kauffman, \& J. Badar, Oxford Research Encyclopedia of Education. Oxford University Press. (2020). https://doi.org/ 10.1093/acrefore/9780190264093.013.926

[3] Vaughn, S., Elbaum, B., \& Boardman, A. G. The Social Functioning of Students with Learning Disabilities: Implications for Inclusion. Exceptionality, 9(1-2), 47-65. (2001). https://doi.org/10.1080/09362835.2001.9666991

[4] Wendelborg, C., \& Tøssebro, J. Educational arrangements and social participation with peers amongst children with disabilities in regular schools. International Journal of Inclusive Education, 15(5), 497-512. (2011). https://doi.org $/ 10.1080 / 13603110903131739$

[5] Kavale, K. A., \& Forness, S. R. Social skill deficits and learning disabilities: A metanalysis. Journal of Learning Disabilities, 226-237. (1996).

[6] Almakanin, H., Alabdallat, B., \& Alnajadat, H. Identifying behavioral problems among students with learning disabilities and its relationship with their social competencies from their teachers' and peers' point view. Jordanian Journal of Educational Sciences, 10(4), 503-516. (2014).

[7] Almeqdad, Q., Bataineh, O., \& Aljarrah, A. The Level of Social Skills amongst Students with and without Learning Disabilities in Jordan According to their Teachers. Jordanian Journal of Educational Sciences, 7(3), 253-270. (2011).

[8] Pavri, S., \& Luftig, R. The Social Face of Inclusive Education: Are Students with Learning Disabilities Really Included in the Classroom? Preventing School Failure: Alternative Education for Children and Youth, 45(1), 8-14. (2001). https://doi.org/10.1080/10459880109599808

[9] Nowicki, E. A. A Meta-Analysis of the Social Competence of Children with Learning Disabilities Compared to Classmates of Low and Average to High Achievement. Learning Disability Quarterly, 26(3), 171-188. (2003). https://doi.org/10.2307/1593650

[10] Hassan, A. Comparative study between learning disabled and normal students in social skills. Umm Al-Qura University Journal of Educational and Psychological Sciences, 1(1). (2009).

[11] Benowitz, A. Social competence of students with learning disabilities using a risk-resilience model [Dissertation]. Fordham University. (2010)

[12] Berti, B. The Syrian refugee crisis: Regional and human security implications. Strategic Assessment, 17(4), 41-53. (2015).

[13] Crock, M., Saul, B., McCallum, R., \& Smith-Khan, L. Syrian refugees with disabilities in Jordan and Turkey. University of Sydney. (2015). https://doi.org/10.13140/RG. 2.1.1485.1044

[14] HelpAge International. Hidden victims of the Syrian crisis: Disabled, injured and older refugees. (2014).

[15] Rohwerder, B. Syrian refugee women, girls, and people with disabilities in Turkey. K4D Helpdesk Report. (2018).

[16] UNICEF. Under Siege: The devastating impact on children of three years of conflict in Syria. Regional Office for the Middle East and North Africa. (2014). 
https://www.unicef.org/publications/files/Under_Siege_Ma rch_2014.pdf

[17] UNHCR. A promise of tomorrow: The effects of UNHCR and UNICEF cash assistance on Syrian refugees in Jordan. (2017). https://www.unhcr.org/

[18] Ministry of Education. School data: All data on schools and students. (2019). https://portal.jordan.gov.jo/wps/portal/Ho me/OpenDataMain/OpenDataUser/\#/viewDataSet/162

[19] Tahraoui, Y. Improve the Social Skills of People with Learning Disabilities. Generation of Human and Social Sciences Journal, 57(1), 67-79. (2019).

[20] Al-Yagon, M. Subtypes of Attachment Security in School-Age Children with Learning Disabilities. Learning Disability Quarterly, 35(3), 170-183. (2012). https://doi.org/10.1177/0731948712436398

[21] Bauminger, N., \& Kimhi-Kind, I. Social Information Processing, Security of Attachment, and Emotion Regulation in Children with Learning Disabilities. Journal of Learning Disabilities, 41(4), 315-332. (2008). https://doi.org/10.1177/0022219408316095

[22] Musa, A. K. J., Meshak, B., \& Sagir, J. I. Adolescents' Perception of the Psychological Security of School Environment, Emotional Development and Academic Performance in Secondary Schools in Gombe Metropolis. Journal of Education and Training Studies, 4(9). (2016). https://doi.org/10.11114/jets.v4i9.1705

[23] Kinsfogel, K. M., \& Grych, J. H. Interparental Conflict and Adolescent Dating Relationships: Integrating Cognitive, Emotional, and Peer Influences. Journal of Family Psychology, 18(3), 505-515. (2004). https://doi.org/10.103 7/0893-3200.18.3.505

[24] Wang, B., Wu, C., \& Huang, L. Emotional safety culture: A new and key element of safety culture. Process Safety Progress, 37(2), 134-139. (2018). https://doi.org/10.1002/pr s. 11953

[25] Zoabi, H., \& Shawareb, E. Emotional Security and Its Relationship with Alienation Among Students in Nazareth District. Dirasat for Humanities and Social Sciences, 46(1), 141-160. (2019).

[26] Alegre, A. Parenting Styles and Children's Emotional Intelligence: What do We Know? The Family Journal, 19(1), 56-62. (2011) https://doi.org/10.1177/1066480710387486

[27] Alaedein, J., \& Alhih, H. Impact of Group Counseling in Reducing Symptoms of Anger Among Children of Syrian Refugees in Jordan. Jordanian Journal of Educational Sciences, 27(4), 21-40. (2018).

[28] Keller, P., \& El-Sheikh, M. Children's emotional security and sleep: Longitudinal relations and directions of effects: Sleep and security. Journal of Child Psychology and Psychiatry, 52(1), 64-71. (2011). https://doi.org/10.1111/j.1 469-7610.2010.02263.x

[29] Williamson, E., Gregory, A., Abrahams, H., Aghtaie, N., Walker, S.-J., \& Hester, M. Secondary Trauma: Emotional Safety in Sensitive Research. Journal of Academic Ethics, 18(1), 55-70. (2020). https://doi.org/10.1007/s10805-019-0 $9348-\mathrm{y}$

[30] Baeva, I. A., \& Bordovskaia, N. V. The psychological safety of the educational environment and the psychological well-being of Russian secondary school pupils and teachers. Psychology in Russia: State of Art, 8(1), 86. (2015). https://doi.org/10.11621/pir.2015.0108

[31] Mishoe, J. N. Academic Optimism and Academic Success: An Explanatory Case Study [Dissertation, The University of Texas at Arlington]. (2013). https://rc.library.uta.edu/uta-ir/ bitstream/handle/10106/11576/Mishoe_uta_2502D_11932. pdf? sequence $=1 \&$ isAllowed $=\mathrm{y}$

[32] Al-Shehri, Z. Emotional Security and Its Relationship with Prosocial Behavior among the Fatherless Orphans in Makkah. Journal of Arab Studies in Education and Psychology, 106(1), 358-381. (2019). https://doi.org/10.12 816/SAEP.2019.49388

[33] Mahmoud, J. Psychological security and its relationship with both social competence and self-confidence among students of the Faculty of Education. Journal of Arab Studies, 13(2), 133-167. (2014).

[34] Maashi, M. Quality of life and its relationship with both social behavior and psychological security among a sample of adolescents. Scientific Journal of the Faculty of Education - Assiut University, 34(2), 232-270. (2018). https://doi.org/10.12816/0049643

[35] Abu Dhuib, A. Psychological Security among High School Syrian Refugee Students in Mafraq Educational Directorate. Al-Shamal Journal for Humanities, 4(1), 109-136. (2019).

[36] Blairdouh, K. A. The Reality of The Psychological Security at The Syrian Refugees Selected Eastern Algerian Cities. Journal of Human Sciences of Umm El-Bouaghi University, 4(1), 951-961. (2017).

[37] Abu al-Ghanam, G., Al-Khaddam, H., \& Naimat, M. Psychological Implications of Syrian Refugee Students in Jordanian Schools according to Some Variables. Al-Manara Journal for Research and Studies, 22(2), 271-302. (2016).

[38] Bang, Hyeyoung. Iraqi Refugee High School Students' Academic Adjustment. Diaspora, Indigenous, and Minority Education, 11(1), 45-59. (2017).

[39] Reilly, Rachael. Disabilities among refugees and conflict-affected populations. Forced Migration Review, 35, 8-10. (2010).

[40] Lyon, G. Reid, et al. "Rethinking learning disabilities." Rethinking special education for a new century, 259-287. (2001).

[41] O'Hara, Jean. Learning disabilities and ethnicity: Achieving cultural competence. Advances in Psychiatric Treatment, 9(3), 166-174. (2003).

[42] Usman, Lantana. " Assessing the Puzzles of Specific Learning Disability Disorder and Support Services for African Refugee Students in K-10 Public Schools of Northern British Columbia." Poetics of Anti-Racism, 107-121. (2006).

[43] Bal, Aydin. Becoming in/competent learners in the United States: Refugee students' academic identities in the figured world of difference. International Multilingual Research Journal, 8(4),271-290. (2014).

[44] Ritter, D. R. Social Competence and Problem Behavior of Adolescent Girls with Learning Disabilities. Journal of 
Learning Disabilities, 22(7), 460-461. (1989). https://doi.org/10.1177/002221948902200714 